\title{
Mulheres que vivem com HIV/aids: vivências e sentidos produzidos no cotidiano
}

\author{
Mariana de Moraes Duarte Oliveira' (iD) 0000-0002-4122-193X \\ Telma Low Silva Junqueira' (iD) 0000-0001-8852-114X \\ 'Universidade Federal de Alagoas, Maceió, AL, Brasil. 57072-970 - \\ secretaria.psi@ip.ufal.br
}

\section{$-$}

\begin{abstract}
Resumo:Neste artigo visou-se compreender como cinco mulheres que vivem com HIV produzem sentidos sobre suas vivências após o diagnóstico de infecção. Realizou-se entrevistas com usuárias de um serviço ambulatorial de um hospital, cuja análise foi fundamentada no referencial teóricometodológico da perspectiva feminista de gênero na interface com as Práticas Discursivas e Produção de Sentidos. Construiu-se mapas dialógicos compostos por três categorias temáticas embasadas nos objetivos propostos e analisou-se como as questões de gênero, dentro de uma sociedade patriarcal e heteronormativa, incidem nas práticas de cuidado e assistência à saúde. Os resultados apontaram para a existência de julgamento moral e preconceito que atravessam e desafiam o manejo do (auto)cuidado dessas mulheres.
\end{abstract}

Palavras-chave: mulheres; HIV/aids; vulnerabilidades; relações de gênero; saúde.

Women Living with HIVlaids: Experiences and Generating Meanings in Daily

Abstract: This paper aims to understand women living with HIV and the way they make sense out of their experiences after the diagnosis of infection. It were conducted interviews with five women, users of a outpatient care in a northeastern capital, whose analysis was based on the methodologic and theory referential of the feminist perspective and in the Discursive Practices and Production of Senses. It were constructed dialogical maps composed by three thematic based on the proposed objectives and it has been analyzed how gender issues, inside a patriarchal and heteronormative society, affect the health care practices and health care. The results reveal for the existence of moral judgement and prejudices that it goes through and challenge the handle of self-care of these women.

Keywords: Women; HIV/aids; Vulnerabilities; Gender relations; Health.

\section{Introdução}

A Síndrome de Imunodeficiência Adquirida (aids) é a fase mais avançada da infecção causada pelo Vírus da Imunodeficiência Humana (HIV), que fragiliza o sistema imunológico do organismo, permitindo que uma pessoa infectada se torne mais suscetível à infecção por outras doenças. A sigla aids será empregada em minúsculo, visto que a palavra aids se tornou equivalente a 'sífilis', 'coqueluche', 'conjuntivite'. Nomes de doenças são substantivos comuns grafados com inicial minúscula, não havendo motivo para aids ser grafada em letras maiúsculas (Cristina CÂMARA; Ronaldo LIMA, 2000).

Viver com HIV não significa o desenvolvimento da aids ou dos sintomas associados. A transmissão do HIV pode se dar por meio de relações sexuais desprotegidas, materiais perfurocortantes ou por transmissão vertical (da mulher para o/a bebê), durante a gestação, parto ou amamentação (BRASIL, 2002). 
A prevenção combinada tem sido considerada uma técnica eficaz na prevenção ao HIV. Consiste no uso simultâneo de diferentes abordagens de prevenção, aplicadas em vários níveis para responder às necessidades específicas de determinados grupos populacionais e de determinadas formas de transmissão do HIV. Envolve intervenções biomédicas que visam à redução do risco à exposição ao vírus, como a utilização dos antirretrovirais (ARVs) para pessoas infectadas pelo HIV e à adoção de estratégias como a Profilaxia Pré-Exposição (PreP) e a Profilaxia PósExposição (PEP), em alguns casos, para pessoas não infectadas pelo vírus; intervenções comportamentais, que contribuem para ampliação de informações e da percepção acerca do vírus e suas consequências; e as estruturais, que buscam mudar as causas ou estruturas centrais que afetam os riscos e as vulnerabilidades ao HIV, envolvendo estigmas e preconceito, discriminação, desigualdades de gênero ou qualquer forma de alienação dos direitos e garantias fundamentais à dignidade humana e à cidadania (BRASIL, 2017a).

O Relatório Informativo - Estatísticas globais sobre HIV 2018 da UNAIDS (2019) - Programa Conjunto das Nações Unidas sobre HIV/aids - destacou que em 2018 havia cerca 37,9 milhões de pessoas vivendo com HIV no mundo, ocorrendo cerca de 1,7 milhão de novas infecções por HIV. No Brasil, segundo o Boletim Epidemiológico de 2018 do Ministério da Saúde (MS), de 2007 a junho de 2018, notificou-se no Sistema de Informação de Agravos de Notificação (SINAN) 247.795 casos de infecção pelo HIV, sendo $169.932(68,6 \%)$ casos em homens e $77.812(31,4 \%)$ em mulheres (BRASIL, $2017 b)$.

No nordeste, nesse mesmo período, foram 42.215, sendo 2.951 notificados pelo SINAN em Alagoas (BRASIL, 2018). Em Maceió, dados da Secretaria do Estado da Saúde de Alagoas (SESAU), contabilizaram, de 2007 a 2017, 1.532 casos de HIV (SESAU, 2018).

Em 2014, a UNAIDS lançou a Declaração de Paris, propondo o fim da epidemia da aids até 2030. Para tanto, os governos ao redor do mundo têm se mobilizado para alcançar a meta $90-90$ 90 de controle, tratamento e redução da epidemia. O intento é que, até $2020,90 \%$ de todas as pessoas vivendo com HIV saberão seu diagnóstico; $90 \%$ de todas as pessoas diagnosticadas receberão tratamento antirretroviral sem interrupções; e $90 \%$ de todas as pessoas recebendo o tratamento antirretroviral alcançarão a carga viral indetectável.

O advento da aids no Brasil coincide com o período de transição democrática, marcado pela reorganização e fortalecimento da sociedade civil, no momento pós-ditadura militar, o que mobilizou ações políticas voltadas também para o campo da saúde. Frente ao crescente número de pessoas infectadas pelo HIV e às constantes violações de direitos às quais eram submetidas, observou-se a articulação de ativistas políticos/as, profissionais de várias áreas, movimento homossexual e setores diversos da sociedade civil em torno da luta contra a epidemia, cujos/as "integrantes provinham das universidades, igrejas, partidos e/ou organizações de militância política de esquerda" (Jane GALVÃO, 2000, p. 38).

Neste contexto, o combate à aids foi concebido no interior do Sistema Único de Saúde (SUS), sendo este o principal pilar de sustentação do programa brasileiro de aids (Maria Inês NEMES; Mário SCHEFFER, 2016). O SUS surgiu com a Constituição Federal de 1988, que prevê a saúde como direito de todas/os e dever do Estado, tendo como princípios doutrinários a universalidade, integralidade e equidade.

A partir da Lei n० 9.313/96, as pessoas que vivem com HIV/aids (PVHA) têm direito ao tratamento universal e gratuito com os ARVs pelo SUS, sendo que o Brasil, já apontado pela ONU como uma referência mundial quanto ao controle da epidemia, apresentou a estabilização de taxas de prevalência, o acesso à medicação e o aumento do número de testes para detecção do vírus. No entanto, no atual contexto, há retrocessos e estagnações quanto à assistência de PVHA, devido à instabilidade do cenário político-econômico (Sonia CORRÊA, 2016).

Para Corrêa (2016), as proposições brasileiras frente à prevenção e à assistência de PVHA têm se mostrado ameaçadas devido ao fortalecimento de movimentos conservadores pautados por um viés biomédico e medicalizante que vai de encontro à perspectiva de direitos humanos e não discriminação que, no passado, marcou a resposta brasileira ao HIV/aids, recuando nas questões de gênero, sexualidade e família, ao assumir visões moralistas sobre temas como saúde e direitos reprodutivos, HIV/aids e educação sexual.

Desde o final de 2013, o país passou a seguir a tendência internacional ao adotar a "estratégia do modelo único", que testa e trata a todos/as independentemente do nível de CD4 ou de carga viral no sangue. Segundo Fernando Seffner e Richard Parker (2016), embora esse modelo de assistência proponha a testagem de forma contínua, não se tem garantido efetivamente a inclusão social e programas de apoio, mantendo-se o recrudescimento de processos de estigma, discriminação e violência social de PVHA, afetando, particularmente, as mulheres que vivem com HIV/aids, uma vez que a infecção está imbricada com questões que envolvem outras esferas de suas vidas, como casamento, maternidade e amamentação, sexualidade e relações de gênero.

Para Solange Rocha, Ana Vieira e Jorge Lyra (2013), a epidemia da aids mantém-se como um importante paradigma para se repensar e discutir as desigualdades sociais, econômicas, de 
gênero, raça e a vivência da sexualidade. Evidencia-se as desigualdades de poder decorrentes do racismo e das relações capitalistas e patriarcais, influenciando diretamente os modos de enfrentamento da epidemia e formas de cuidado das mulheres consigo mesmas.

A construção da sociedade em moldes patriarcais ainda hoje impõe regras, no âmbito sexual, para homens e mulheres, incidindo, inclusive, no processo saúde-doença e na vulnerabilidade às Infecções Sexualmente Transmissíveis (IST). Historicamente, cabe à mulher as funções de mãe, esposa e 'dona do lar', estando a sua sexualidade, por muito tempo, atrelada essencialmente à reprodução. Assim, as mulheres estão associadas a uma postura passiva e encontram-se em um nível desfavorável em relação aos homens, no acesso a educação, trabalho e sustentabilidade econômica.

Essa condição também implica uma repressão da sexualidade feminina, que só pode ser exercida "livremente" com a sanção do amor que, para muitas, assume um sentido de abnegação a partir do qual negam a si mesmas em função do outro (Regina BARBOSA; Wilza VILELLA, 1996). Dificulta-se, assim, a apreensão do próprio conceito de prevenção, já que há mulheres que não se sentem à vontade e seguras para negociar ou propor a adoção de práticas preventivas.

Só na segunda metade dos anos 90 o MS focalizou a sua atenção em ações voltadas para as mulheres, por meio da prevenção quanto à transmissão vertical e de campanhas que incentivavam a negociação do uso do preservativo com os companheiros. Porém, tais ações ora se davam de um modo imperativo quanto ao uso de preservativos, ora conservador quanto ao debate da sexualidade e suas práticas (ROCHA; VIEIRA; LYRA, 2013).

A vulnerabilidade que afeta as mulheres triplica quando se soma a desigualdade de gênero às questões socioeconômicas e raciais. Para Stella Taquette (2009), mulheres negras/pardas apresentam maior vulnerabilidade em relação às brancas quanto ao acesso à educação, à saúde, ao trabalho e à previdência, vitimadas ainda pelo racismo estrutural. A autora aponta que os índices socioeconômicos também mostram condições menos favoráveis a essa parcela da população, assim como os indicadores de saúde e educação, sendo a escolaridade menor e a mortalidade materna maior. Da mesma forma, mulheres pobres parecem ser colocadas em situação desigual, já que grande parte se dedica ao trabalho não remunerado (o cuidado da própria família) e/ou trabalha como domésticas, acessando menos o mercado de trabalho econômica e socialmente mais bem valorizado e remunerado.

José Ricardo Ayres et al. (2013) abordam o conceito de vulnerabilidade a partir de três esferas, individual, social e programática, que abarcam diferentes graus e naturezas de suscetibilidade de indivíduos e coletividades à infecção, ao adoecimento e à morte pelo HIV. A primeira se relaciona aos comportamentos que criam a oportunidade de se infectar ou adoecer. Porém, a exposição às situações de maior risco não deve ser atrelada apenas à vontade das pessoas, mas considerar o grau de consciência delas acerca dos possíveis danos e o poder de transformação a partir de consciência. No plano social, estão as questões vinculadas ao acesso à informação e à qualidade dos serviços de saúde; nível geral de saúde da população; condições de bem-estar social etc. O plano programático trata das ações institucionais especificamente voltadas para o problema do HIV/aids (AYRES et al., 2013). Logo, o conceito de vulnerabilidade complexifica as dimensões de vida a serem consideradas quando se trata da suscetibilidade à infecção do HIV.

O interesse em abordar a temática das mulheres que vivem com HIV surgiu a partir da vivência em um hospital universitário, enquanto psicóloga residente de um programa de residência multiprofissional em saúde vinculado a uma universidade pública do nordeste. Por meio de atendimentos individuais e da participação em grupos de convivência com usuárias/os do setor foi possível trabalhar questões para além da infecção, como as relações laborais, familiares, gravidez e amamentação, relações com o/a companheiro/a, e como essas implicavam no processo saúde-doença e nos modos de lidarem com o (auto)cuidado.

Portanto, este trabalho visa à compreensão de como mulheres que vivem com HIV/aids constroem sentidos sobre suas vivências após o diagnóstico da infecção, no contexto de uma estrutura de sociedade ainda predominantemente patriarcal, racista, classista e heteronormativa e como isso influencia na construção das relações de gênero que estabelecem nos seus cotidianos, que também se articulam com outros marcadores sociais, como raça, geração, classe e sexualidade.

\section{Método}

Esta é uma pesquisa qualitativa, realizada em 2018, fundamentada no referencial teóricometodológico da perspectiva feminista de gênero na interface com as Práticas Discursivas e Produção de Sentidos (Mary Jane SPINK; Helena LIMA, 2013).

Foi desenvolvida junto com 05 mulheres usuárias do Serviço de Atendimento Especializado (SAE) de um hospital-escola vinculado ao SUS, situado em uma capital do nordeste. O SAE é composto por uma equipe multiprofissional de saúde que oferta atendimento ambulatorial a pessoas com doenças infecciosas, como HIV/aids, hepatites virais B e C, HTLV e tuberculose. 
Realizou-se 05 entrevistas semiestruturadas, que ocorreram no próprio hospital, com duração em média de 40 minutos. As mulheres foram apresentadas à pesquisa, aprovada pelo Comitê de Ética em Pesquisa, expressando desejo de participar, firmado por meio da assinatura do Termo de Consentimento Livre e Esclarecido (TCLE). Todas viviam com HIV, tinham entre 23 e 58 anos e autorizaram a gravação em áudio das entrevistas. As pesquisadoras compunham a equipe multiprofissional de residentes do ambulatório, que é um dos cenários de prática da residência, de modo que buscaram, no sistema informatizado do setor, quais mulheres com HIV eram atendidas, com destaque para a idade e tempo de diagnóstico, a fim de abarcar uma maior diversidade. Assim, as mulheres que se dirigiram ao ambulatório para serem consultadas foram convidadas a participar.

As participantes foram diagnosticadas com HIV entre os anos de 2003 a 2017. Uma foi encaminhada para o serviço após o adoecimento do marido; outra iniciou o tratamento em outro hospital e mudou de serviço para continuar o acompanhamento com a médica com quem havia iniciado o tratamento; e as outras três foram diagnosticadas durante o parto. Todas, geralmente, são acompanhadas mensalmente no serviço, participam das atividades no grupo voltado para pessoas que vivem com HIV/aids.

Os nomes usados são fictícios, escolhidos pelas próprias mulheres. Inicialmente, aplicou-se um breve questionário sociodemográfico com informações autodeclaradas sobre idade, sexo, raça/etnia, estado civil, ocupação, se tinham filhos/as ou não, orientação sexual e identidade de gênero. Também se utilizou um roteiro norteador, que trazia uma questão disparadora: "conta um pouco sobre sua história de vida" e, a partir do que elas dialogavam, abordava-se temáticas que contemplassem os objetivos da pesquisa, como: socialização de gênero; processo de diagnóstico da infecção; mudanças na rotina; situações de preconceito e possibilidades de enfrentamento.

Após a transcrição das entrevistas, elaborou-se 04 mapas dialógicos compostos por 03 categorias temáticas embasadas nos objetivos propostos a fim de organizar trechos das falas das mulheres condizentes com cada categoria. O método possibilitou que participantes e autoras produzissem sentidos sobre HIV, de modo a se tecer um processo dialógico de (re)pensar certas práticas e posicionamentos assumidos ao longo da vida.

Segundo Spink e Lima (2013), os mapas constituem instrumentos de visualização que têm duplo objetivo: subsidiar o processo de interpretação e facilitar a comunicação dos passos subjacentes ao processo interpretativo. A partir disso, foram destacadas 03 categorias relacionadas aos sentidos produzidos no diálogo com as mulheres: (1) vulnerabilidades e relações de gênero; (2) desafios; e (3) situações de preconceito e enfrentamento.

A perspectiva feminista de gênero permitiu pensar como as vivências dessas mulheres, no que diz respeito à sexualidade, sentimentos, saúde e prevenção, estão imbricadas em relações de poder que podem implicar a manutenção de padrões de gênero hegemônicos. Considera-se também que as histórias das mulheres entrevistadas não contam a realidade de todas as mulheres que vivem com HIV, visto que esta pesquisa é pensada para trazer as experiências e narrativas de modo situado, parcial e complexo, sem a pretensão de generalizar e construir verdades (Donna HARAWAY, 1995).

Apresenta-se um breve perfil das mulheres:

Ana, 32 anos, heterossexual, branca, auxiliar de serviços gerais concursada, solteira, reside no interior do estado com o companheiro soroconcordante, e possui 04 filhas. Descobriu o HIV em 2017, durante a última gestação.

Eloá, 23 anos, heterossexual, negra, solteira, dona de casa. Mora com o companheiro sorodiscordante em um sítio no interior do estado. Tem 02 filhas e 01 filho. Descobriu o HIV em 2012, durante o parto da primeira filha.

Maria, 41 anos, heterossexual, negra, viúva, trabalha como cuidadora de idosos/as, vive sozinha na capital e tem 01 filho e 01 filha. Descobriu o HIV em 2004, quando o marido adoeceu.

Neguinha, 33 anos, heterossexual, parda, dona de casa, solteira, mora com o companheiro sorodiscordante no interior do estado e possui 01 filho e 01 filha. Descobriu o HIV em 2005, durante o parto.

Rosana, 58 anos, heterossexual, branca, solteira, desempregada - trabalhou como empregada doméstica. Vive sozinha na capital e tem 01 filho. Descobriu o HIV em 2003, quando o companheiro começou a adoecer.

\section{Resultados e discussões}

Organizou-se os resultados em 03 subseções, que abarcam questões relacionadas à: 1) vulnerabilidades; 2) desafios enfrentados quanto à adesão ao tratamento antirretroviral; e 3) enfrentamento quanto a situações de estigmas e preconceitos.

\section{Saúde, vulnerabillidades e relações de gênero}

A construção do imaginário social acerca do HIV/aids, historicamente, é associada à promiscuidade e comportamentos "desviantes", partindo de um viés normatizador e estigmatizante. 
Além de estimular práticas discriminatórias, tal noção invisibilizava outras populações que, com o decorrer dos anos, mostraram-se vulneráveis ao vírus devido às mudanças de perfil ocorridas a partir de variantes geográficos, geracionais, socioeconômicos, raciais, sexuais e de gênero.

A heterossexualização e a feminização do HIV/aids estão relacionadas também às formas de pensamentos, concepções e representações que determinam, entre outras ações, o não uso dos preservativos nas relações sexuais no contexto do casamento (Larissa RODRIGUES; Miriam PAIVA; Jeane OLIVEIRA; Sheva NÓBREGA, 2012).

Todas as mulheres afirmaram manter, somente, relações heterossexuais. Quatro destacam que foram infectadas enquanto estavam em relacionamentos estáveis com os parceiros. Uma delas afirma que fez a testagem no hospital, porém não foi buscar o resultado de imediato, descobrindo o HIV apenas durante o parto, em 2005.

Me chamaram e disseram que eu tava com HIV, aí pra mim foi um choque né? Porque eu casei com o pai da minha filha, aí então acho que ele pegou de outras mulheres, me traiu né? [...] Quando eu descobri esse problema. Eu me senti traída, né? Porque você confia numa pessoa e a pessoa faz o mal pra você. [...] Num parava de chorar. Aí fui me conformando, né? Que Deus num ia deixar eu morrer (Neguinha).

A gente tá junto já temos uns 3 anos ou mais. Usava mais o preservativo quando o remédio tinha acabado ou quando era dia de tomar injeção e eu não tinha tomado, então a gente se precavia desse jeito. Mas como diz o outro, eu tinha total confiança (Ana).

Após o diagnóstico, quatro das que foram infectadas durante o relacionamento com os companheiros permaneceram com eles. Duas ficaram viúvas em decorrência da aids e uma iniciou outro relacionamento posteriormente. Apenas uma acredita ter sido infectada antes do relacionamento atual, sendo o parceiro sorodiferente. Duas permanecem sem parceiros.

Os sentidos produzidos nos convidam a pensar sobre como o amor e fidelidade atravessam questões relacionadas à prevenção à saúde, pois as mulheres parecem sentir-se seguras quanto ao não uso de preservativos quando se encontram em relacionamentos afetivos estáveis, refletindo o perigo do amor romantizado. O modelo de amor romântico pode implicar para as mulheres um ideal de amor construído à base de renúncias pessoais e de uma relação de submissão ao homem (Esperanza BOSCH, 2007). Assim, embora quatro das cinco tivessem informações anteriores sobre o HIV e os modos de infecção, não faziam uso de preservativos de forma contínua.

[...] Já, já tinha ouvido falar. Muita gente dizia que o HIV matava, só que eu nunca imaginava que eu ia ter pego ela, né? (Neguinha).

Já, já [conhecia sobre a doença], só que porque naquela época como eu confiava muito nele porque na época eu tinha o quê? Tinha 17 pra 18 anos. Só que como eu confiava nele... Pode acontecer com os outros, mas com você, você acha que nunca vai acontecer né? (Maria).

[...] Eu sabia que existia, mas não sabia como era que pegava (Eloá).

A informação prévia sobre o HIV e os "perigos do sexo desprotegido" parecem insuficientes para garantir a prevenção, de acordo com o discurso de algumas. Por isso a relevância de se atentar aos aspectos subjetivos, sociais, econômicos, culturais etc. que circulam e se inscrevem no cotidiano dessas mulheres.

Algumas orientações médicas, centradas na prevenção, ainda são repassadas a partir do princípio de que a falta de saúde é provocada por formas de viver "inadequadas". As informações sobre sexo seguro e o uso do preservativo atuam como dispositivos condicionantes de comportamentos atrelados à ideia de que manter uma boa saúde, viver na linha do equilíbrio é a única forma de conseguir a liberdade e proteção (Graziele ARRAES, 2015). É nesse sentido que as questões de gênero, sexualidade, raça e etnia, classe, geração se interseccionam e possibilitam a reflexão em torno de um cuidado em saúde que não seja higienista, prescritivo, controlador dos corpos, práticas e subjetividades, heteronormativo, racista, machista, punitivo etc.

Segundo Joan Scott (1995), o conceito de gênero possibilita um meio de "decodificar o significado e de compreender as complexas conexões entre várias formas de interação humana" (p. 89). A autora teoriza gênero a partir de duas dimensões: a primeira considera "gênero" enquanto um elemento constitutivo de relações sociais baseadas nas diferenças percebidas entre os sexos, e a segunda, como uma forma primária de significar as relações de poder. Logo, a perspectiva de gênero nos permite visualizar as representações simbólicas e sociais atribuídas ao "ser homem" e "ser mulher" pautadas numa relação binária, complementar e oposta: dominador-dominada. Nesse quadro, às mulheres cabe uma posição de subjugação, que inclusive se dá em suas relações afetivas, de modo que parece ser mais facilmente aceito o homem exercer uma sexualidade mais ativa e manter relacionamentos com mais de uma parceira, conforme se observa:

Acho que ele nem sabia como foi que pegou, com quem surgiu, com quem foi, porque ele era namorador [risos]. Aí esses homens namorador saem com uma mulher pra cá, outra pra 
lá e não sabe nem com quem foi e o tempo também que ele já tava, né? Porque se ele já tinha com certeza há alguns tempos atrás ele já tava e não sabia, né? (Maria).

Eu tenho certeza que foi dele que eu peguei, porque eu não me relacionava com nenhuma outra pessoa e homem que sempre sai com as coisinha deles por fora, né? (Neguinha).

Mas como a mulher vai pegar se não for do homem? [...] A não ser que ela, por exemplo, trabalhe em algum hospital e se fure, e vá aplicar alguma injeção, e se contaminar. Mas aí já é outra coisa, né? Mas assim eu acho que o homem é mais fácil porque ele se envolve com mais gente. [...] (Rosana).

Para Heleieth Saffioti (2001), é possível que casais construam uma relação igualitária, desprovida de hierarquias, porém isto raramente ocorre, uma vez que a convivência democrática entre homens e mulheres contraria todo o contexto social no qual acontece. As relações de poder desiguais, nos casais heterossexuais, dificultam, inclusive, o diálogo quanto à adoção de práticas preventivas, até mesmo nos casos de casais sorodiferentes. Mesmo sendo um casal soroconcordante, é ideal o uso do preservativo durante as relações sexuais, já que a não utilização pode propiciar a reinfecção e o aumento de carga viral. Entre as mulheres, observou-se que é comum, para as que afirmam se manter numa relação estável, não utilizar o preservativo, de acordo com o desejo dos parceiros.

Ele bebia demais e como bebia demais, não dava nem pra conversar. Às vezes eu saía pro trabalho, ele saía pra beber, chegava bebo, às vezes não chegava. E era assim. Ele não tocava não no assunto (Rosana).

Ele não quer. Só que ele já fez o teste ano passado e deu que não. Aí por mim, ele usaria, mas ele não quer. Aí acha ruim quando eu falo. Eu só queria o direito dele, né? Só que ele já sabe. Sempre digo a ele, né? Pra ele usar. Mas num quer. Teimoso que só (Neguinha).

A gente usou, eu usei uns dois anos aí depois a gente parou. Agora não tá usando não (Eloá).

Segundo Naila Santos et al. (2009), o perfil das mulheres com HIV reitera que a prática de multiplicidade de parceiras/os é mais frequente e socialmente aceitável nos homens do que nas mulheres. E, mesmo quando estas não concordam com o comportamento dos parceiros, nem sempre dispõem de meios materiais e simbólicos para sair da relação ou mudar os seus termos.

Três das entrevistadas não trabalham fora de casa. Uma se mantém por meio do trabalho do parceiro e outra da pensão de viuvez. A terceira encontra-se desempregada. A quarta passou a trabalhar fora de casa após o falecimento do parceiro e somente uma é concursada. A dependência financeira é também um ponto crucial quanto ao enfrentamento das desigualdades de poder no âmbito das relações afetivas com os companheiros.

[...] Você me contou, fazer o quê? Vamo conviver normal. Nunca pensei em separar porque tinha os menino. Pensava muito nos meninos. E também sair de casa assim com dois meninos pequenos, se eu fosse querer me relacionar com outra pessoa, seria bem mais complicado, mas pra mim foi normal (Maria).

Como aponta Kátia Guimarães (1996), para muitos homens, a infecção por via sexual é fruto de um "pecado" menor que ocorre em espaços públicos, fora de casa. Já para muitas mulheres, a infecção fruto da relação com o/a parceiro/a parece romper a noção do vínculo indissolúvel entre amor e sexo incidindo nas dimensões associadas às funções de mãe e esposa.

Três das entrevistadas descobriram a infecção durante a gestação ou o parto, o que modificou, inclusive, as formas de lidar com os/as filhos/as e suas expectativas frente à amamentação e futuras gestações.

E agora que eu fiz a operação, que foi cesáreo, aí essa diferença eu tive, porque eu sempre fui uma pessoa que gostava de ter filho, queria ter mais, só que aí apareceu esse problema, aí eu tive essa já com medo, tenho até que fazer os exames pra ver como tá as coisinha dela, aí eu optei, eu e meu companheiro, por não ter mais (Ana).

Pra mim foi a pior coisa. Meu sonho era amamentar e não pude [...] Teve tempo que eu não queria nem que me abraçassem. A enfermeira ia pra lá, ia me abraçar e eu dizia, 'Não. Não, V'. Aí ela disse [...] 'Essa doença não pega assim'. Aí ela começou a me explicar como era. Aí depois ficou melhor pra mim e pras minhas filhas. Com menos medo. Não queria dar água no mesmo copo que eu. Sei lá, [...] não queria cheirar minhas filhas (Eloá).

Eu achava que a criança já nascia, né? Mas aí eu tive o S., foi o processo, né? De tomar remédio. Aí resolvi me operar. Mas senão acho que ainda queria ter outro, né? Mas eu pensei, então me operei (Neguinha).

A testagem para HIV, a indicação de uso de preservativo, a inclusão do/a parceiro/a na rede assistencial, a prescrição de vacinas para doenças específicas etc. são alguns dos protocolos que visam garantir a saúde e a vida da mulher mãe, bem como evitar a transmissão vertical do HIV para o/a bebê, para aquelas que vivem com HIV/aids e desejam ser mães. A maternidade, então, deve ser vista como um direito fundamental das mulheres que a desejam, abrangendo as que 
vivem com HIV/aids, sendo dever do Estado ofertar medidas necessárias para garantir seu exercício (Ana Maria LOPES; Denise ANDRADE, 2017).

As mulheres expressam que a descoberta do vírus causa, inicialmente, estranhamentos, confrontos e tentativas de diálogos com os parceiros. No entanto, também demonstram como a permanência de uma sociedade predominantemente heteropatriarcal fomenta que características como multiplicidade de parceiras/os, sexualidade ativa e posicionamentos mais autônomos e determinantes ainda sejam considerados como "próprios" dos homens, mantendo-se realidades desiguais pouco questionáveis - o que tende a provocar nessas mulheres uma "aceitação" e naturalização da/na forma como constroem seus relacionamentos afetivo-sexuais e as implicações que isso gera em suas vidas pessoais e cotidianas.

Diante disso, destaca-se a importância dos serviços de saúde no fomento à autonomia das mulheres no que se refere às escolhas de métodos para um sexo mais seguro, como a oferta de preservativos femininos, informações acerca das profilaxias PreP e PEP ao HIV, estímulo à prática de erotização do preservativo e de relações afetivo-sexuais mais equitativas, prazerosas e diversas (BRASIL, $2017 \mathrm{~b}$ ).

Juliana Sampaio (2006) reitera a importância de se romper com a transmissão de informação que sustenta normatizações de condutas sexuais calcadas no poder prescritivo médico e no coroamento do uso da camisinha como única forma de prevenção sexual possível, findando na responsabilização do sujeito por sua condição de risco frente ao HIV. Destaca que a própria erotização do preservativo demonstra a viabilidade de políticas públicas que considerem e respeitem as diversidades sexuais, valorizando o prazer como um aspecto da saúde.

\section{Desafios frente d̀ gestão do autoculdado entre/com mulheres em contextos (des)favoráveis}

As doenças de modo geral podem representar um ponto de ruptura na vida, exigindo uma reorganização da forma como a pessoa lida com sua rotina, rede social, laboral e familiar, além de mudanças frente ao autocuidado, o que pode gerar dúvidas, sentimento de insegurança, medo e ansiedade, implicando na vivência de um sofrimento psíquico. Michael Bury (2011), ao realizar uma pesquisa com pacientes com artrite reumatoide, observa que uma doença crônica pode romper com as estruturas da vida cotidiana e as formas de conhecimento da pessoa, englobando vivências de dor, sofrimento e até de morte.

No caso das PVHA, é comum ainda terem que lidar com estigmas e preconceitos, o que pode interferir no processo de aceitação da infecção.

Aceitar eu nunca aceitei, né? [...] A gente, como diz a história, tenta não lembrar, né? Somente isso. Porque se ficar lembrando toda hora, vem negócio ruim na cabeça, aí não dá! [...] Eu falo nessas coisas, mas eu não gosto não, sabe? Às vezes dá vontade de chorar. Só que aí toda hora eu não posso tá chorando, né? (Rosana).

Para as entrevistadas, as mudanças ocorridas em suas vidas após a infecção envolvem especialmente a adequação do medicamento às suas rotinas e as visitas regulares ao serviço de saúde.

[...] meu dia a dia tá normal, faço tudo que eu fazia antes. A única diferença é que tem aquele horário sagradinho que tomar o remédio, não pode esquecer, pra saúde da gente mesmo, né? Pra gente viver melhor, viver bem (Ana).

O que mudou é que agora tem que vim pra médico, tem que tá se tratando, tem que tá se cuidando. E antigamente eu não tinha essa preocupação, né? Você tem que ficar vindo pra médico, mais medicamento, fazer exame (Neguinha).

Elas apontam alguns desafios que encontram no manejo do autocuidado, sobretudo quanto ao uso do medicamento no cotidiano, que parece se tornar um problema, especialmente quando, por alguma razão, a mulher decide (ou não consegue) não compartilhar o diagnóstico com a família, que pode querer saber o motivo da medicação, o porquê de seu uso etc. Destacam também como dificultadores as condições econômicas e de moradia; o contexto laboral, no que se refere ao (des)conhecimento do/a empregador/a quanto à infecção e possíveis estigmas e preconceitos; e os próprios efeitos colaterais da medicação.

Porque logo quando eu comecei a tomar tinha um que era pra ir pra geladeira. Aquele era horrível, porque também no tempo que eu fui viajar, esse tinha que ficar na geladeira e não era todo canto que tinha geladeira, principalmente no trabalho. Depois de um tempo que a menina colocou um freezer aí eu tinha que pôr na geladeira, embalar, colocar num potinho. Aí isso que me incomodou. Mas depois que mudou ficou uma "bença"! (Maria).

A medicação que no início foi difícil porque tem muito medicamento que é ruim. Teve vários que já fiquei com os olhos amarelos, não me dava aí saía trocando, né? Mas eu tô com esse outro aí agora tá bom, né? Mas tem momento que... Quer dizer, ano passado mermo eu 
parei de tomar, passei um ano sem vir aqui. Aí voltei esse já de novo, aí agora eu tô indo, tomando remédio. Às vezes penso em parar aí penso e volto de novo (Neguinha).

A questão da medicação avançou quanto à distribuição, redução da quantidade de comprimidos ingeridos ao longo do dia e sua preservação, o que facilita a vida de usuários/as que, inclusive, vivem em situações de pobreza. Porém, de acordo com Veriano Terto Junior et al. (2016), o MS tem mantido uma postura resistente e conservadora quanto à incorporação de novos medicamentos, o que a médio e longo prazo pode inviabilizar o tratamento de pessoas que vivem com HIV. A combinação medicamentosa de ARVs utilizada no Brasil apresenta-se defasada em relação a países como Estados Unidos, Inglaterra e Espanha, especialmente devido aos efeitos colaterais a médio e longo prazo (JUNIOR et al., 2016). Para os autores, esse conservadorismo pode aumentar a desigualdade entre os países no acesso às novas combinações de ARVs que seriam mais benéficas e poderiam minimizar os agravos clínicos, sociais e econômicos que podem ser trazidos por efeitos colaterais das medicações.

Para além das motivações pessoais e do contexto social de cada usuário/a, a interação profissional de saúde-usuário/a é importante para a vinculação e revinculação de uma pessoa ao serviço de saúde. A prática do acolhimento parece fundamental em qualquer relação de cuidado, no vínculo entre os sujeitos, na recepção e escuta das pessoas, podendo ser considerada uma ferramenta que possibilita: a humanização do cuidado; amplia o acesso da população aos serviços de saúde; assegura a resolução dos problemas; coordena os serviços; e vincula a efetivação de relações entre profissionais e usuários/as (Adriana LOPES et al., 2015).

Para as mulheres, o serviço de saúde pode funcionar como um impulsionador ou como uma barreira para a continuidade do cuidado, destacando o que consideram primordial para a atuação de um/a profissional no atendimento de PVHA.

[...] Desde o primeiro dia que eu cheguei fui bem atendida. Às vezes a gente fica com receio de chegar lá e uma pessoa vai ficar meio, porque esse problema, [...] depois eu aprendi que eles e todos aqui tratam exclusivamente e muitas vezes apropriado desse tipo de coisa, então já estão acostumados a lidar com isso, têm todos os conhecimentos (Ana).

Aquela Dra. Y., gostava dela não. Porque quando eu vim há 3 meses atrás porque eu tava falhando o remédio, pra tomar direitinho, aí ela perguntou se eu queria alguma coisa com o tratamento mesmo ou não queria. Ela disse que não podia tá dando remédio assim e eu não tá tomando controlado. [...]. Quando eu pedi um atestado médico pra dar entrada no meu benefício, quase que ela num me dava. [...] Acho que deve atender a pessoa bem, né? Uma porque tão ganhando pra isso e também é o serviço deles, né? (Eloá).

Outro desafio é a questão do acesso aos direitos sociais, como o Benefício de Prestação Continuada (BPC) e o transporte público gratuito. O BPC foi criado pela Lei Orgânica de Assistência Social para suprir as necessidades básicas de famílias de baixa renda, beneficiando, apenas, pessoas acima de 65 anos ou que vivem com alguma deficiência cuja renda familiar per capita seja inferior ou igual a 1/4 do salário mínimo. No caso das PVHA, só é disponibilizado quando há um agravamento da condição de saúde e o consequente desenvolvimento da aids.

Aí que o meu filho tá em São Paulo aí eu sempre viajava muito pra lá, né? Quando eu tava com meu dinheirinho porque meu benefício foi cortado. Aí quando eu tava com meu dinheirinho, fui em 2012, passei um ano, voltei em 2013 [...] (Rosana).

A não regulamentação da gratuidade do transporte público também aparece como uma barreira. Em Maceió, foi aprovada, em 2015, a Lei n 6.370, que revogava a Lei n 4.635, de 1997, que dispunha sobre a gratuidade no pagamento de tarifas do sistema de transporte público, de modo que apenas teriam direito aquelas pessoas que tenham desenvolvido a aids, excluindo as que viviam com HIV. A partir de maio de 2018, após denúncias de usuários/as, foi movida uma ação civil pelo Ministério Público para assegurar que qualquer PVHA tenha o direito à gratuidade nos transportes públicos, considerando esta uma questão afeita ao direito à saúde, que compromete diretamente a continuidade do tratamento (PORTAL SETE SEGUNDOS, 03/05/2018).

\section{Estratégias de enfrentamento e resistência diante do preconceito, estigmas $\Theta$ desinformação}

A infecção por HIV ainda se mantém sob um julgamento moral, sendo tomada como uma doença que atinge pessoas que têm um comportamento considerado transgressor, imoral e socialmente reprovável (Maria Rita de Cássia ALMEIDA, 2004). Por isso, muitas, ao descobrirem que têm o HIV, acabam, por medo, se isolando e não compartilhando o diagnóstico com familiares e pessoas de confiança.

Duas das entrevistadas conversaram com a família de maneira voluntária; uma preferiu contar só ao esposo soroconcordante; uma, somente ao filho e a uma colega; e a última teve o HIV revelado sem seu consentimento para pessoas de sua família e seu esposo. 
Meus pais sabem, meus irmãos sabem. Todo mundo me deram apoio. [...] Meus filhos vieram saber depois de uns anos, porque como eles eram menor não tinha necessidade de falar com eles naquela época, né? Eu falei com eles agora, depois da segunda vez que eles fizeram os exames. Que tiveram que repetir com 14 anos (Maria).

Não tenho coragem [de contar para a família]. Só entre a gente. Eu não tive coragem e acho que não tenho. Porque querendo ou não, já mudou muito o mundo, mas hoje em dia, o preconceito ainda é muito, então ou parte da família ou desconhecido, a gente não sabe qual vai ser a reação das pessoas (Ana).

Rapaz, contar, contar assim de repente, sem querer querendo eu contei pra uma colega aí acho que aí foi o fundo do poço. Por sinal essa pessoa nem fala mais comigo hoje. [...] da minha família só quem sabe é meu filho e mais ninguém (Rosana).

O sigilo sobre a sorologia do/a usuário/a é garantido pela Lei n 12.984/2014, que criminaliza atos de discriminação contra PVHA, no trabalho ou escola, no atendimento em serviços de saúde ou na divulgação dessa condição com o intuito de ofender a dignidade. Contudo, persistem o medo e o receio, visto que informações equivocadas sobre formas de transmissão ainda são costumeiramente reproduzidas:

[...] quando a tia do meu marido disse, teve muita gente que ficou assim, com nojo, sei lá... Muita gente ainda tem lá. Algumas pessoas se afastaram. Só vejo o povo dizendo 'não pode tomar água no mesmo copo que ela não'. Muita coisa... "Não vá pra casa dela, não sei o quê". O povo da família mermo (Eloá).

[...] nem contei pra minha patroa ainda, porque eu cuido de um senhorzinho de idade, né? Dou banho nele, dou o medicamento dele, eu tenho o maior cuidado com ele, né? Assim, não mexo com negócio de injeção nem nada, dou comprimido, [...] dou a alimentação dele, mas não me sinto confiável em contar. Porque tenho medo dela me despedir e eu também tô precisando do trabalho (Maria).

Uma irmã minha que eu tenho, ela me tratava assim, bem, mas depois ela começou a separar, não queria mais tocar em mim, não queria mais fazer minhas unhas, então percebi que já ficou diferente, né? O namorado dela mermo mandava ela separar os prato porque achava que passava pelos prato, aí eu comecei a sofrer um pouco, né? Porque eu comecei a perceber que tava com, num queria eu, né? (Neguinha).

Porém, o sigilo também pode perpetuar o estigma ao tratar o HIV/aids como um diagnóstico que não pode ser mencionado ou exposto. De início, a própria divulgação e notícias sobre o HIV/ aids, apesar de fomentar a conscientização e esclarecimento, tornava o tema também estigmatizante (Marcos de ALMEIDA; Daniel MUNOZ, 1999).

Letícia Tunala (2002) destaca a importância de serviços de saúde incorporarem estratégias que envolvam familiares em atividades educativas e de aconselhamento nos SAE como um meio de beneficiar a qualidade de vida das mulheres que vivem com HIV. O conflito de uma mulher acerca de contar (ou não) sobre sua condição está ancorado no sentimento de confiança de que será acolhida e apoiada. Se a experiência for positiva, ela pode se sentir mais confiante para falar sobre sua privacidade; caso contrário, pode experimentar o sentimento de rejeição (Fernanda FERREIRA, 2007).

Após iniciar o tratamento no serviço de saúde, algumas participantes relatam ter desmistificado as informações e adquirido novas formas de entender o HIV.

Descobri que é uma doença generalizada como outras que têm por aí. Não com a mesma intensidade, como tipo quem tem hipertensão, não tem cura, diabetes... Você tem o tratamento, mesma coisa do HIV. Sei que aquilo lá por enquanto não tem cura, né? Mas tem o controle, tem o tratamento, e tem que ser feito. Isso que eu aprendi aqui (Ana).

E eu acho que, pelo que me deram explicação: eu tô com um corte. Aí uma outra pessoa aqui do meu outro lado também tá com um corte. Eu encosto ali, daí eu acho que já passou, né? Porque é assim, né? Aí foi isso que eu entendi, né? E também perguntando pra Dra $Y$. se isso poderia pegar em copo, talher, essas coisas, e ela disse que não, tem nada a ver (Rosana).

O estigma da infecção ainda pode trazer uma sensação de finitude quanto aos projetos de vida no âmbito pessoal e/ou profissional (Isabel MALISKA et al., 2009). As emoções que surgem após um diagnóstico positivo estão relacionadas com sentimentos vivenciados em situaçõeslimite impostas pela vida, que variam de acordo com as interpretações subjetivas de cada pessoa acerca do conceito construído socialmente:

Eu parei na sexta, né? Meu sonho era terminar, terminar os estudos e fazer um cursinho de cabelereira, de manicure. Era meu sonho. [E não conseguiria agora?] Acho que não. Por causa desse meu problema. Do HIV. Só penso nisso (Eloá).

Eu tava fazendo sétima e oitava. Em 2015. Aí parei de estudar. Voltei em 2015 depois de muitos anos, voltei em 2015, aí não concluí, né? Parei de novo. Deu preguiça. [Planeja voltar?] 
Tô pensando. Porque assim, moro no interior, né? [...] Aí eu digo com 33 anos, terminar os estudos pra quê, né? Não tenho mais idade (Neguinha).

A fé e a religião também podem atuar como mecanismos de enfrentamento às questões que surgem com o diagnóstico de HIV/aids ou se tornarem mais uma barreira. A religiosidade pode ser considerada uma dimensão integrante do humano quando se concebe que a saúde é atravessada por uma série de fatores biológicos, subjetivos, ambientais, socioeconômicos, espirituais, culturais e políticos. Assim, pode atuar de vários modos na vida das pessoas que vivem e convivem com HIV/aids, como apontam as mulheres. A fé em um ser supremo pode funcionar como um amparo/suporte no desafio da pessoa se reposicionar pessoal e socialmente após a descoberta do diagnóstico. Mas pode ser também uma via de autoculpabilização frente à infecção adquirida, tornando-se um fator de desproteção no autocuidado decorrente da possível ideia de falta de/pouca fé diante da possibilidade de uma cura milagrosa, operada por Deus etc.

Quer dizer, eu creio que Deus vá me curar, mas no tempo dele, né? Então, enquanto Deus não me curar, tem que ir pro médico, tomar remédio, aí eu vou levando (Neguinha).

Ele [o marido] não acredita não, óia. [...] Sim, ele diz que eu não tenho fé em Deus não. Ele diz que Deus cura tudo... Fica conversando isso (Eloá).

Porque se não fosse Deus não sei se eu estaria assim não com tanta... serenidade. Eu digo que eu sou uma pessoa muito calma. [...] Porque a gente não sabe do que vai morrer. Eu tô com esse problema, mas não sei o que vai acontecer comigo. [...] Eu não me preocupo muito com essa doença. [...] Tento não pensar, porque a gente não sabe o destino da gente, mas eu sempre peço a Deus, mas Graças a Deus, nunca senti nada, nada, nada (Maria).

É relevante que o serviço de saúde acolha e respeite a religiosidade e crenças de cada usuário/a, bem como a não crença em seres de natureza não material. Tais fatores podem influenciar diretamente na forma com que a pessoa lida com o processo de adoecimento, com o diagnóstico, a adesão a um tratamento e a manutenção de sua continuidade. Uma pessoa, ao buscar um serviço de saúde, pode estar à procura de um acolhimento aos seus anseios e angústias, o que, muitas vezes, é ignorado ao se atentar simplesmente à infecção. Nessas situações, o/a usuário/a acaba sendo visto/a pela ciência como um indivíduo numérico, respondendo a uma categorização de diagnóstico e a uma uniformização de terapêutica, o que torna esse universo não familiar (JUNGES et al., 2011).

\section{Considerações finais}

Esta pesquisa incitou reflexões e problematizações sobre as dimensões que fazem parte do processo saúde-doença. Percebemos que, para promover uma saúde integral, não é possível dissociá-la das discussões em torno dos padrões hegemonicamente heteronormativos, machistas, racistas, classistas e excludentes. Sabemos que toda e qualquer pessoa está suscetível à infecção pelo vírus HIV. Porém, se considerarmos o processo de marginalização e desigualdade que algumas vivenciam diariamente, seja de ordem econômica, social, de raça e/ou de gênero, podemos refletir sobre quem está mais vulnerável às consequências desses padrões hegemônicos.

O processo de descoberta do HIV acarreta sentimentos conflituosos e mudanças na rotina, exige adaptações, podendo gerar uma sensação de finitude na/para a pessoa. As mulheres falam sobre as barreiras que encontram no manejo do autocuidado e na adesão ao tratamento antirretroviral e as associam, inclusive, ao julgamento moral que ainda hoje recai sobre a PVHA. Destacam ainda o desafio de ter que lidar com estigmas e preconceitos reproduzidos socialmente.

A pesquisa nos convida a re-pensar sobre como as questões de gênero influenciam fortemente as práticas de cuidado à saúde das mulheres e as situações de vulnerabilidade às quais estão expostas. Ainda hoje, para muitas, é difícil negociar com o/a parceiro/a o uso de métodos preventivos devido a uma postura machista adotada pela sociedade.

Cabe ressaltar, portanto, a importância de se refletir e discutir como as práticas profissionais em saúde têm sido produzidas, se estão enviesadas por posturas biologicistas, heteropatriarcais, classistas e/ou racistas e como se pode avançar na promoção e prevenção à saúde de forma que não se limitem a uma reprodução e imposição de informações descontextualizadas, prescritivas e violadoras de direitos humanos.

\section{Referências}

ALMEIDA, Maria Rita de Cássia Barreto. A trajetória silenciosa de pessoas portadoras do HIV contada pela história oral. 2004. Dissertação (Mestrado em Enfermagem) - Programa de Pós-Graduação em Enfermagem, Setor de Ciências da Saúde da UFPR, Universidade Federal do Paraná, Curitiba, PR, Brasil.

ALMEIDA, Marcos de; MUNOZ, Daniel Romero. "Relação médico-paciente e paciente instituição na aids: o direito à informação e à confidência; a discriminação; o abandono e a coerção". Revista 
Bioética, São Paulo, v. 1, n. 1, p. 49-53, 1999. Disponível em http://revistabioetica.cfm.org.br/index.php/ revista_bioetica/article/view/477/294. ISSN 0104-1401. Acesso em 15/10/2019.

ARRAES, Graziele Regina de Amorim. Entre o desejo e a culpa: a transformação do comportamento sexual e as mudanças da noção de risco nas campanhas de prevenção à aids no Brasil (19812013) e Estados Unidos durante a década de 1980. 2015. Tese (Doutorado em História) - Programa de Pós-Graduação em História, Faculdade de História da UFSC, Universidade Federal de Santa Catarina, Florianópolis, SC, Brasil.

AYRES, José Ricardo de Carvalho Mesquita et al. "Adolescência e aids: avaliação de uma experiência de educação preventiva entre pares". Interface, Botucatu, v. 7, n. 12, p. 113-128, 2013. Disponível em https://www.scielosp.org/article/icse/2003.v7n12/123-138/. ISSN 1807-5762. Acesso em 15/10/2019.

BARBOSA, Regina Maria; VILLELA, Wilza Vieira. "A trajetória feminina da AIDS". In: PARKER, Richard; GALVÃO, Jane (Orgs.). Quebrando o silêncio: mulheres e Aids no Brasil. Rio de Janeiro: RelumeDumará, 1996. p. 17-32.

BOSCH, Esperanza Fiol et al. "Del mito del amor romántico a la violencia contra las mujeres en la pareja". Estudios e investigaciones, Ministerio de Igualdad, Madri, 2007. Disponível em http:// www.inmujer.migualdad.es/mujer/mujeres/estud_inves/770.pdf. ISBN 978-84-691-3157-2. Acesso em 08/04/2018.

BRASIL. Ministério da Saúde. Secretaria de Vigilância em Saúde, Departamento de Vigilância, Prevenção e Controle das Infecções Sexualmente Transmissíveis, do HIV/Aids e das Hepatites Virais. Prevenção Combinada do HIV: Bases Conceituais para Profissionais, Trabalhadores(as) e Gestores(as) de Saúde. 1. ed. Brasília: Ministério da Saúde, 2017a. 123p.

BRASIL. Ministério da Saúde. Secretaria de Vigilância em Saúde, Departamento de Vigilância, Prevenção e Controle das Infecções Sexualmente Transmissíveis, do HIV/Aids e das Hepatites Virais. Boletim Epidemiológico - Aids e IST, ano V. n. 1. Brasília: Ministério da Saúde, 2017b. 64p.

BRASIL. Ministério da Saúde. Secretaria de Vigilância em Saúde, Programa Nacional de DST e Aids. Direitos Humanos e HIVIAids: avanços e perspectivas para o enfrentamento da epidemia no Brasil. 1. ed. Brasília: Ministério da Saúde, 2018. 168p.

BRASIL. Ministério da Saúde. Coordenação Nacional de Doenças Sexualmente Transmissíveis e Aids. AIDS: etiologia, clínica, diagnóstico e tratamento. Brasília: Unidade de Assistência, 2002. 17p.

BURY, Michael. "Doença crônica como ruptura biográfica". Tempus - Actas de Saúde Coletiva Ciências Sociais em Saúde, v. 5, n. 2, p. 41-55, 2011 . Disponível em http://tempusactas.unb.br/ index.php/tempus/article/view/963. ISSN 1982-8859. http://dx.doi.org/10.18569/tempus.v5i2.963. Acesso em 02/10/2019.

CÂMARA, Cristina; LIMA, Ronaldo Massauer. "Histórico das ONGs/Aids e sua contribuição no campo das lutas sociais". Cadernos ABONG, São Paulo, n. 28, p. 40, 2000.

CORRÊA, Sonia. "A resposta brasileira ao HIV e à AIDS em tempos tormentosos e incertos". In: ABIA. Associação Brasileira Interdisciplinar de AIDS. Mito vs Realidade: sobre a resposta brasileira à epidemia de HIV e AIDS em 2016. Rio de Janeiro: Observatório Nacional de Políticas de AIDS; UNITAID, 2016. p. 9-17.

FERREIRA, Fernanda Cristina. As condições que levam as mulheres soropositivas ao HIV/aids a abrir a privacidade de suas informações às equipes do Programa Saúde da Família. 2007. Dissertação (Mestrado) - Programa de Pós-Graduação em Enfermagem em Saúde Coletiva, Escola de Enfermagem da Universidade de São Paulo, Universidade de São Paulo, São Paulo, SP, Brasil.

GALVÃO, Jane. AIDS no Brasil: a agenda de construção de uma epidemia. Rio de Janeiro: ABIA; 34, 2000.

GUIMARÃES, Kátia. "Nas raízes do silêncio: A representação cultural da sexualidade feminina e a prevenção do HIV/AIDS". In: RICHARD, Parker; GALVÃO, Jane (Orgs.). Quebrando o silêncio: mulheres e Aids no Brasil. Rio de Janeiro: Relume-Dumará, 1996. p. 89-114.

HARAWAY, Donna. "Saberes localizados: a questão da ciência para o feminismo e o privilégio da perspectiva parcial". Cadernos Pagu, v. 5, p. 07-41, 1995. Disponível em https://periodicos.sbu. unicamp.br/ojs/index.php/cadpagu/article/view/1773/1828. ISSN 1809-4449. http://dx.doi.org/ 10.1590/S0104-83332011000100002. Acesso em 15/10/2018. 
JUNIOR, Veriano Terto et al. "A luta continua: avanços e retrocessos no acesso aos antirretrovirais no Brasil". In: ABIA. Associação Brasileira Interdisciplinar de AIDS. Mito vs Realidade: sobre a resposta brasileira à epidemia de HIV e AIDS em 2016. Rio de Janeiro: Observatório Nacional de Políticas de AIDS; UNITAID, 2016. p. 39-51.

JUNGES, José Roque et al. "Saberes populares e cientificismo na estratégia saúde da família: complementares ou excludentes?". Revista Ciência \& Saúde Coletiva, Rio de Janeiro, v. 16, n. 1 1, 2011 1. Disponível em http://www.scielo.br/scielo.php?script=sci_arttext\&pid=\$1413-8123201100 1200005\&lng=en\&nrm=iso. ISSN 1413-8123. http://dx.doi.org/10.1590/S1413-81232011001200005. Acesso em 04/05/2018.

LOPES, Adriana Santos et al. "Acolhimento na atenção básica em saúde: relações de reciprocidade entre trabalhadores de saúde". Saúde e Debate, Rio de Janeiro, v. 39, n. 104, p. 114-123, 2015. Disponível em http://www.scielo.br/scielo.php?script=sci arttext\&pid=S0103-1 10420150001001 14\& Ing=en\&nrm=iso. ISSN 0103-1 104. http://dx.doi.org/10.1590/0103-1 10420151040563. Acesso em 10/ $04 / 2018$.

LOPES, Ana Maria D'Ávila; ANDRADE, Denise Almeida de. "O direito fundamental à maternidade da mulher gestante soropositiva". Revista Direito e Liberdade, v. 19, n. 1, p. 13-33, 2017. Disponível em http://www.mpsp.mp.br/portal/page/portal/documentacao_e_divulgacao/doc_biblioteca/ bibli_servicos_produtos/bibli_informativo/bibli_inf_2006/Rev-Dir-e-Liberd_v.19_n.01.01.pdf. ISSN 2177-1758. Acesso em 15/10/2019.

MALISKA, Isabel Cristina Alves et al. "Percepções e significados do diagnóstico e convívio com o HIV/AIDS". Revista Gaúcha de Enfermagem, Porto Alegre, v. 30, p. 85-91, 2009. Disponível em http:/ /seer.ufrgs.br/RevistaGauchadeEnfermagem/article/view/5966. E-ISSN 1983-1447. Acesso em 11/ $04 / 2018$.

NEMES, Maria Inês Baptistela; SCHEFFER, Mário. "Desafios da assistência às pessoas que vivem com HIV e AIDS no Brasil". In: ABIA. Associação Brasileira Interdisciplinar de AIDS. Mito vs Realidade: sobre a resposta brasileira à epidemia de HIV e AIDS em 2016. Rio de Janeiro: Observatório Nacional de Políticas de AIDS; UNITAID, 2016. p. 33-38.

PORTAL SETE SEGUNDOS. "MP garante acesso gratuito ao transporte coletivo para pessoas com HIV/ AIDS". Portal Sete Segundos, Maceió, 03/05/2018. Disponível em https://maceio.7segundos.com.br/ noticias/201 8/05/03/1 10102/mp-garante-acesso-gratuito-ao-transporte-coletivo-para-pessoas-comhiv-aids.html. Acesso em 25/05/2018.

ROCHA, Solange; VIEIRA, Ana; LYRA, Jorge. "Silenciosa conveniência: mulheres e AIDS". Revista Brasileira de Ciência Política, Brasília, n. 11, p. 119-141, 2013. Disponível em http://www.scielo.br/ scielo.php?script $=$ sci_arttext\&pid=S0103-33522013000200005\&lng=en\&nrm=iso. ISSN 01033352. http://dx.doi.org/10.1590/S0103-33522013000200005. Acesso em 24/03/2018.

RODRIGUES, Larissa Silva Abreu; PAIVA, Miriam Santos; OLIVEIRA, Jeane Freitas de; NÓBREGA, Sheva Maia da. "Vulnerabilidade de mulheres em união heterossexual estável à infecção pelo HIV/Aids: estudo de representações sociais". Rev. Esc. Enferm. USP, São Paulo, v. 46, n. 2, p. 349-355, 2012. Disponível em https://www.revistas.usp.br/reeusp/article/view/40955/44468. Acesso em 21/09/2019.

SAFFIOTI, Heleieth lara Bongiovani. "Contribuições feministas para o estudo da violência de gênero". Cadernos Pagu, Campinas, n. 16, p. 115-136, 2001. Disponível em http://www.scielo.br/ scielo.php?script=sci_arttext\&pid=S0104-83332001000100007. ISSN 0104-8333. http://dx.doi.org/ 10.1590/S0104-83332001000100007. Acesso em 15/10/2018.

SAMPAIO, Juliana. A construção de novas políticas públicas como caminho para a prevenção da Aids. 2006. Tese (Doutorado em Saúde Pública) - Centro de Pesquisa Aggeu Magalhães - CPqAM, Fundação Oswaldo Cruz - FIOCRUZ, Pernambuco, Recife, Brasil.

SANTOS, Naila J. S. et al. "Contextos de vulnerabilidade para o HIV entre mulheres brasileiras". Cadernos de Saúde Pública, Rio de Janeiro, v. 25, supl. 2, p. s321-s333, 2009. Disponível em http://www.scielo.br/ scielo.php?script=sci_arttext\&pid=S0102-311X2009001400014\&Ing=en\&nrm=iso. ISSN 1678-4464. http://dx.doi.org/10.1590/S0102-311X2009001400014. Acesso em 20/03/2018.

SEFFNER, Fernando; PARKER, Richard. "A neoliberalização da prevenção do HIV e a resposta brasileira à AIDS". In: ABIA. Associação Brasileira Interdisciplinar de AIDS. Mito vs Realidade: sobre a resposta brasileira à epidemia de HIV e AIDS em 2016. Rio de Janeiro: Observatório Nacional de Políticas de AIDS; UNITAID, 2016. p. 24-32. 
SESAU - SECRETARIA DE SAÚDE DO ESTADO DE ALAGOAS. Total de casos de HIV + Residentes no município de Maceió, Diagnóstico no período de 2007 a 2017. Maceió: Governo de Alagoas, 2018.

SPINK, Mary Jane; LIMA, Helena. "Rigor e visibilidade: a explicação dos passos da interpretação". In: SPINK, Mary Jane (Org.). Práticas discursivas e produção de sentidos no cotidiano: aproximações teóricas e metodológicas. São Paulo: Cortez, 2013. p. 71-99.

SCOT, Joan Wallach. "Gênero: uma categoria útil de análise histórica". Educação e Realidade, Porto Alegre, v. 20, n. 2, p. 71-99, 1995. Disponível em https://seer.ufrgs.br/educacaoerealidade/article/ view/71721/40667. ISSN 2175-6236. Acesso em 24/03/2018.

TAQUETTE, Stella. "Feminização da AIDS e adolescência". Revista Adolescência e Saúde, Rio de Janeiro, v. 6, n. 1, p. 33-40, 2009. Disponível em http://www.adolescenciaesaude.com/detalhe_artigo. asp?id=39. ISSN 2177-5281. Acesso em 20/03/2018.

TUNALA, Letícia Gaspar. "Fontes cotidianas de estresse entre mulheres portadoras de HIV". Rev. Saúde Pública, v. 36, n. 4, p. 24-31, 2002. Disponível em http://www.scielo.br/pdf/rsp/v36n4s0/ 11 160.pdf. ISSN 0034-8910. http://dx.doi.org/10.1590/S0034-89102002000500005. Acesso em 14/ 10/2019.

UNAIDS. Relatório informativo - Atualização da AIDS 2019. Estatísticas Globais sobre HIV 2018. UNAIDS, 2019. Disponível em https://unaids.org.br/wp-content/uploads/2019/07/2019_UNAIDS_GR2019_Fact Sheet_pt_final.pdf. Acesso em 02/10/2019.

Mariana de Moraes Duarte Oliveira (mari.duarte@ @hotmail.com) é psicóloga formada pela UFAL, especialista em saúde do adulto e do idoso pelo Programa de Residência Multiprofissional em Saúde do Adulto/a e do/a Idoso/a da UFAL. Possui interesses em: Psicologia e Saúde, gênero e sexualidade, perspectiva feminista de gênero.

Telma Low Silva Junqueira (telma.low@ip.ufal.br) é psicóloga formada pela UFPE, mestra e doutora em estudos de gênero pela Universidade de Valência/Espanha, Professora Adjunta da UFAL e tutora de psicologia no Programa de Residência Multiprofissional em Saúde do/a Adulto/a e do/a Idoso/a da UFAL. Desenvolve trabalhos e pesquisas sobre: Psicologia, saúde e questões de gênero; Formação em saúde e questões de gênero; Mito do amor romântico e Violência de gênero.

\section{COMO CITAR ESSE ARTIGO DE ACORDO COM AS NORMAS DA REVISTA}

OLIVEIRA, Mariana de Moraes Duarte; JUNQUEIRA, Telma Low Silva. "Mulheres que vivem com HIV/aids: Vivências e Sentidos Produzidos no Cotidiano". Revista Estudos Feministas, Florianópolis, v. 28, n. 3, e61140, 2020.

\section{CONTRIBUIÇÃO DE AUTORIA}

Mariana de Moraes Duarte Oliveira - concepção, coleta e análise dos dados, elaboração do manuscrito, redação e discussão de resultados.

Telma Low Silva Junqueira - concepção, análise dos dados, elaboração do manuscrito, redação e discussão de resultados.

\section{FINANCIAMENTO}

Não se aplica.

\section{CONSENTIMENTO DE USO DE IMAGEM}

Não se aplica.

\section{APROVAÇÃO DE COMITÊ DE ÉTICA EM PESQUISA}

A pesquisa foi aprovada pelo comitê de ética em pesquisa da Universidade Federal de Alagoas tendo como número do parecer 2.429.381.

CONFLITO DE INTERESSES

Não se aplica. 
LICENÇA DE USO

Este artigo está licenciado sob a Licença Creative Commons CC-BY International. Com essa licença você pode compartilhar, adaptar, criar para qualquer fim, desde que atribua a autoria da obra.

HISTÓRICO

Recebido em 29/01/2019

Reapresentado em 05/11/2019

Aprovado em 17/01/2020

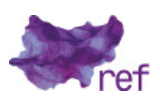

